\title{
Marine collagen peptides protect against early alcoholic liver injury in rats
}

\author{
Bing Lin, Feng Zhang, Yongchao Yu, Qinghao Jiang, Zhaofeng Zhang, Junbo Wang and Yong Li* \\ Department of Nutrition and Food Hygiene, School of Public Health, Peking University, Beijing 100191, \\ People's Republic of China
}

(Submitted 12 January 2011 - Final revision received 25 April 2011 - Accepted 29 June 2011 - First published online 7 September 2011)

\begin{abstract}
Marine collagen peptides (MCP) have been reported to exhibit antioxidative activity, which is the common property of numerous hepatoprotective agents. Previous studies have shown that MCP have biological functions including anti-hypertension, anti-ulcer, anti-skin ageing and extending the life span. However, its role in alcoholic liver injury remains unknown. The present study aimed to investigate the effects of MCP on early alcoholic liver injury in rats. Rats were administered with alcohol at a dose of $6 \mathrm{~g} / \mathrm{kg}$ body weight intragastrically per $\mathrm{d}$ to induce early liver injury, which was then evaluated by serum markers and histopathological examination. Treatment with MCP could reverse the increased level of serum aminotransferase and reduce hepatic histological damage. In addition, MCP attenuated the alteration in serum superoxide dismutase and malondialdehyde levels. MCP also counteracted the increased levels of total cholesterol and TAG. However, no significant difference was observed in the contents of alcohol dehydrogenase both in liver and serum protein of rats. These findings suggest that MCP have a protective effect on early alcoholic liver injury in rats by their antioxidative activity and improving lipid metabolism.
\end{abstract}

Key words: Marine collagen peptides: Alcoholic liver injury: Antioxidants: Lipid metabolism

Alcoholism has become a serious health problem all over the world. The incidence of alcoholic liver disease (ALD) has been increasing rapidly in China ${ }^{(1)}$. ALD is also the major cause of liver cirrhosis in the Western world. Treatment of ethanolrelated illness costs more than 1.5 billion dollars/year and the illness causes loss of productivity in the USA alone ${ }^{(2)}$. The most widely diagnosed forms of ALD are alcoholic fatty liver, acute alcoholic hepatitis and alcoholic cirrhosis ${ }^{(3)}$.

Many pathways are considered to be involved in ALD, such as oxidative stress, mitochondrial damage and inflammatory factors $^{(4,5)}$. Oxidative stress that plays a critical role in the process of liver damage is the result of an imbalance between pro-oxidants and antioxidants. The evidence of alcoholinduced oxidative stress is extensive ${ }^{(6,7)}$. As alcohol takes a high percentage of the total energy intake in alcoholics, the balance of carbohydrate, lipids and proteins is altered. The metabolic disturbance of nutrients may also be involved in $\mathrm{ALD}^{(8)}$. Furthermore, the gradually increasing activity of hepatic alcohol dehydrogenase $(\mathrm{ADH})$ was observed to be due to the long-term intake of alcohol ${ }^{(9)}$.

Although many efforts have been ploughed into the treatment of ALD, there is no universally satisfactory therapy to prevent or reverse the ALD process in humans ${ }^{(10)}$. Some endogenous bioactive peptides, such as ghrelin ${ }^{(11)}$, bradykinin ${ }^{(12)}$, vasoactive intestinal peptide ${ }^{(13,14)}$ and brain natriuretic peptide $^{(15)}$, have been reported to have protective effects against liver injury induced by concanavalin A, carbon tetrachloride or acetaminophen. Although incomprehensive and non-systemic, several exogenous bioactive peptides including Ganoderma lucidum peptides ${ }^{(16)}$, Shahepatic ${ }^{(17)}$ and corn peptides ${ }^{(18)}$ have been reported to alleviate liver injury. Hepatoprotective agents from both plants and animals are attracting more attention today. Marine collagen peptides (MCP) are compounds of low-molecular-weight peptides derived from the skin of chum salmon (Oncorbynchus keta) by enzymatic hydrolysis. The various multifunctional properties of MCP have been described already, including anti-hypertension ${ }^{(19)}$, extending the life $\operatorname{span}^{(20)}$, anti-skin ageing ${ }^{(21)}$ and anti-ulcer ${ }^{(22)}$. Previous research has indicated that MCP have a strong antioxidative activity $^{(23)}$ and could improve lipid metabolism ${ }^{(24)}$. However, the effect of MCP on alcoholic liver injury is not yet known.

In the present study, we investigated the effects of MCP on early alcoholic liver injury in rats. It has been proved that females are more susceptible to alcohol-induced liver injury than males ${ }^{(25,26)}$. So, we chose female rats in the present study. Liver injury was evaluated by biochemical parameters and histopathological changes. In addition, we detected malondialdehyde (MDA), superoxide dismutase (SOD), lipid,

Abbreviations: ADH, alcohol dehydrogenase; ALD, alcoholic liver disease; ALT, alanine aminotransferase; AST, aspartate aminotransferase; MCP, marine collagen peptides; MDA, malondialdehyde; SOD, superoxide dismutase; TC, total cholesterol. 
protein and $\mathrm{ADH}$ levels in serum or liver to find the possible mechanisms of the effects.

\section{Materials and methods \\ Materials and reagents}

Commercial kits used for the determination of total SOD and MDA in serum $\mathrm{ADH}$ and protein in liver tissue were purchased from Jiancheng Institute of Biotechnology (Nanjing, China). Ethanol, acetaldehyde and other chemicals used were of analytical grade and purchased from Beijing Chemical Company (Beijing, China).

\section{Preparation and identification of marine collagen peptides}

MCP, which were derived from the skin of wild-caught chum salmon $(O$. keta; average body weight $1.47 \mathrm{~kg}$ ), were donated by CF Haishi Biotechnology Limited Company (Beijing, China). In brief, fish skin was cleaned and the adherent tissue was scraped manually by a scalpel. Then, the skin was minced and defatted by vigorous stirring in chill water. The materials were emulsified in distilled water and added into complex protease $(3000 \mathrm{U} / \mathrm{g}$ protein), including $7 \%$ tryp$\sin , 65 \%$ papain and $28 \%$ alkaline proteinase. The hydrolysate was then centrifuged to remove impurity. After that, the liquid was separated through a ceramic membrane $(200 \mu \mathrm{m})$ for its purification. The mineral salt was removed from the liquid through a procedure of nanofiltration. Then, the purified liquid was condensed by cryoconcentration under vacuum at $70^{\circ} \mathrm{C}$, with an evaporation rate of $500 \mathrm{~kg} / \mathrm{h}$. When the concentration of the condensed liquid was almost 30 Baume degrees, it was decoloured with $12 \%$ of active carbon at $75^{\circ} \mathrm{C}$ for $1 \mathrm{~h}$, and then the carbon was removed by filtration. Most of the water was removed by spray drying with a pressure of $20 \mathrm{MPa}$, and MCP powder was thus obtained.

The MCP sample contains about $90 \%$ hydrolysed protein, $6.0 \%$ ash, $1.4 \%$ carbohydrate, $2.5 \%$ water and $0.1 \%$ fat. HPLC (Waters Corporation, Milford, MA, USA) of the peptide sample was performed using a Phenomenex C18 column $(10 \times 250 \mathrm{~mm})$ and a mixture of acetonitrile and $0.05 \mathrm{~mol} / 1 \mathrm{phos}-$ phate buffer $(\mathrm{pH} 3 \cdot 2 ; 10: 90)$ as the mobile phase with a flow rate of $2.0 \mathrm{ml} / \mathrm{min}$, monitored at $208 \mathrm{~nm}$ using a Waters 486 tunable UV detector. Then, the molecular weight distribution of the sample was ascertained by LDI-1700 matrix-assisted laser desorption ionisation time-of-flight MS (Liner Scientific, Inc., Reno, NV, USA). In addition, the amino acid composition was further analysed by an H835-50 automatic amino acid analyser (Hitachi, Tokyo, Japan). The result indicated that the molecular weight distribution of MCP was 100-860 Da. Furthermore, $85.86 \%$ of their molecular weight distributed between 300 and $860 \mathrm{Da}$. So, the main composition of MCP was oligopeptides. The amino acid composition of MCP is shown in Table 1.

\section{Animals and treatment}

A total of fifty-two female Sprague-Dawley rats (10 weeks old, weighing 230-250g) were obtained from the Animal Service of Health Science Center, Peking University. The
Table 1. Amino acid composition of marine collagen peptides

\begin{tabular}{lc}
\hline Amino acid & $\begin{array}{c}\text { No. of residues/ } \\
100 \text { residues }\end{array}$ \\
\hline Gly & 23.77 \\
Glu & 12.22 \\
Ala & 6.59 \\
Ser & 4.23 \\
Pro & 9.79 \\
Val & 2.94 \\
Leu & 4.64 \\
Hyp & 7.51 \\
Asp & 7.29 \\
Lys & 5.66 \\
Arg & 6.08 \\
His & 1.61 \\
Phe & 2.51 \\
Thr & 2.53 \\
lle & 2.57 \\
Tyr & 0.03 \\
Met & 0.03 \\
\hline
\end{tabular}

conditions were as follows: a filter-protected, air-conditioned room with controlled temperature $\left(25 \pm 28^{\circ} \mathrm{C}\right)$, relative air humidity $(60 \pm 5 \%)$ and a $12 \mathrm{~h}$ light $-12 \mathrm{~h}$ dark cycle (lights on at 07.30-19.30 hours). Animal treatment and maintenance were carried out strictly in accordance with the Principle of Laboratory Animal Care (NIH publication no. 85-23, revised 1985) and the guidelines of the Peking University Animal Research Committee (www.lab.pku.edu.cn).

\section{Experimental design}

All rats were fed with a modelled AIN-93M rodent diet (Vital River Limited Company, Beijing, China), with casein as the main protein source. After the acclimatisation period of 1 week, animals were randomly divided into five groups: normal control group ( $n$ 10); alcohol control group ( $n$ 12); three groups ( $n$ 10, each) for low $(0 \cdot 225 \mathrm{~g} / \mathrm{kg}$ per d), medium $(0.45 \mathrm{~g} / \mathrm{kg}$ per $\mathrm{d})$ and high $(0.9 \mathrm{~g} / \mathrm{kg}$ per $\mathrm{d})$ doses of MCP. Body weight and food consumption were measured every week. The rats were orally administered with alcohol $(50 \%, \mathrm{v} / \mathrm{v})$ at a dose of $6 \mathrm{~g} / \mathrm{kg}$ per $\mathrm{d}$, except the rats in the normal group that received equivalent distilled water. After $1 \mathrm{~h}$, the rats of the three intervention groups were intragastrically administered with additional MCP while the others received an equal volume of vehicle as control. The study lasted for a total of 4 weeks. After $12 \mathrm{~h}$ of the last alcohol treatment, blood was obtained and serum was separated by centrifugation at $3000 \mathrm{rpm}$ for $10 \mathrm{~min}$. Portions of the liver were then obtained for histopathological and biochemical assays.

\section{Biochemical assays}

The levels of alanine aminotransferase (ALT), aspartate aminotransferase (AST), total proteins, albumin, albumin:globulin ratio, total cholesterol (TC) and TAG in serum were detected by an automatic biochemistry analyser (Hitachi, Tokyo, Japan), and SOD activity and MDA level in serum, and the contents of $\mathrm{ADH}$ and protein in the liver homogenate were determined by the detection kits according to the manufacturer's protocols. 
Table 2. Effects of marine collagen peptides (MCP) on the change in body weight (Mean values and standard deviations, $n 8-11 /$ group)

\begin{tabular}{|c|c|c|c|c|c|c|c|c|c|}
\hline \multirow[b]{2}{*}{ Groups } & \multirow[b]{2}{*}{$n$} & \multicolumn{2}{|c|}{ 1st week } & \multicolumn{2}{|c|}{ 2nd week } & \multicolumn{2}{|c|}{ 3rd week } & \multicolumn{2}{|c|}{ 4th week } \\
\hline & & Mean & SD & Mean & SD & Mean & SD & Mean & $\mathrm{SD}$ \\
\hline Normal control & 10 & $16 \cdot 91$ & $9 \cdot 71$ & $17 \cdot 18$ & $7 \cdot 20$ & 12.90 & $7 \cdot 89$ & $9 \cdot 01$ & $6 \cdot 66$ \\
\hline $\begin{array}{l}\text { Alcohol control } \\
\text { MCP }\end{array}$ & 11 & $2 \cdot 24^{\star}$ & $10 \cdot 88$ & $15 \cdot 68$ & $6 \cdot 34$ & $10 \cdot 91$ & $5 \cdot 25$ & $9 \cdot 21$ & $16 \cdot 71$ \\
\hline Low dose & 8 & -1.74 & $10 \cdot 12$ & $14 \cdot 88$ & $8 \cdot 62$ & 11.06 & $9 \cdot 0$ & $12 \cdot 04$ & $6 \cdot 16$ \\
\hline Medium dose & 10 & $2 \cdot 14$ & 6.94 & $15 \cdot 20$ & 4.96 & $9 \cdot 70$ & $8 \cdot 17$ & $9 \cdot 49$ & $8 \cdot 86$ \\
\hline High dose & 9 & $2 \cdot 7$ & $7 \cdot 30$ & $13 \cdot 89$ & $4 \cdot 79$ & $6 \cdot 89$ & $11 \cdot 42$ & $16 \cdot 07$ & $12 \cdot 53$ \\
\hline
\end{tabular}

* Mean values was significantly different from those of the normal control group $(P<0.05)$.

\section{Histopathological observation}

Portions of the tissues were obtained from the same lobe of the liver in each rat and were immediately fixed in $10 \%$ $(\mathrm{v} / \mathrm{v})$ formaldehyde, embedded in paraffin and cut into $5 \mu \mathrm{m}$-thick sections, which were then stained with haematoxylin and eosin and observed under a light microscope (Nikon Y-FL light microscope; Nikon Corporation, Tokyo, Japan).

\section{Statistical analysis}

Results are expressed as mean values and standard deviations. Data were tested for homogeneity at first and then were evaluated by means of a one-way ANOVA test followed by a post hoc least significant difference test if variances were equal or Tamhane's T2 test if variances were not equal. The statistics compared with the alcohol-treated control group were presented. A $P$ value $<0.05$ was considered significant.

\section{Results}

\section{General state}

There were forty-eight rats that survived over 4 weeks and gained weight during this period. There were four rats that did not survive over 4 weeks: one in the alcohol control group; two in the low-dose MCP group and one in the highdose MCP group. After intragastrically administered with alcohol at a dose of $6 \mathrm{~g} / \mathrm{kg}$, most of the rats behaved excitedly such as unsteady walking and accelerated breathing. At the first week, the weights of the rats administered with alcohol were reduced significantly $(P<0 \cdot 05)$. However, there was no significant difference in the following 3 weeks, indicating that all animals received adequate nutrition after adapting to alcohol. MCP could not restore the change in body weight significantly compared with alcohol-treated rats (Table 2).

\section{Serum alanine aminotransferase and aspartate aminotransferase levels}

Serum ALT and AST activities were used to evaluate early alcoholic liver injury. The AST level was increased nearly by 2 -fold while the ALT level increased by $25 \%$ only, respectively, over the values of normal rats after 4 weeks with alcohol intake by intragastric administration (AST: 47.009 (SD 15.58) v. 26.49 (SD 15.04); ALT: 51.52 (SD 7.83) v. 42.79 (SD 5.12)). The MCP treatment showed the protection against alcohol-induced liver injury in rats by the decrease in the elevation of ALT and AST levels, especially in the high-dose group (Table 3). There was no significant increase in the ratio of AST:ALT with alcohol intake $(P=0 \cdot 271$, alcohol control group $v$. normal control group). However, after the MCP treatment, there was a decrease in the ratio to nearly normal $(P=0 \cdot 269$, low-dose MCP group $v$. alcohol control group).

\section{Serum malondialdehyde and superoxide dismutase levels}

Serum total SOD level was decreased after the alcohol treatment (81.57 (sD 31.46) v. 101.66 (sD 36.18) U/ml), but the intervention of MCP exhibited protection against alcoholinduced SOD depletion (low-dose group: $P<0.05$; Fig. 1). Although the medium- and high-dose groups also had a reversion of SOD depletion, the difference was not significant.

Table 3. Effects of marine collagen peptides (MCP) on serum alanine aminotransferase (ALT) and aspartate aminotransferase (AST) levels in rats

(Mean values and standard deviations, $n 8-11 /$ group)

\begin{tabular}{|c|c|c|c|c|c|c|c|}
\hline \multirow[b]{2}{*}{ Groups } & \multirow[b]{2}{*}{$n$} & \multicolumn{2}{|c|}{ ALT (IU/l) } & \multicolumn{2}{|c|}{ AST (IU/I) } & \multicolumn{2}{|c|}{ AST:ALT ratio } \\
\hline & & Mean & SD & Mean & SD & Mean & SD \\
\hline Normal control & 10 & $42 \cdot 79$ & $5 \cdot 12$ & $26 \cdot 49$ & $15 \cdot 04$ & 0.63 & 0.37 \\
\hline $\begin{array}{l}\text { Alcohol control } \\
\mathrm{MCP}\end{array}$ & 11 & $51.52 \dagger$ & $7 \cdot 83$ & $47.09 \dagger$ & $15 \cdot 58$ & 0.93 & 0.33 \\
\hline Low dose & 8 & $45 \cdot 85$ & 4.55 & $27 \cdot 09^{*}$ & $14 \cdot 88$ & 0.61 & 0.33 \\
\hline Medium dose & 10 & $45 \cdot 85$ & $8 \cdot 40$ & $30 \cdot 36^{\star}$ & $13 \cdot 36$ & 0.69 & 0.37 \\
\hline High dose & 9 & $41.69^{*}$ & $10 \cdot 50$ & $26 \cdot 83^{\star}$ & 32.62 & 0.80 & 1.24 \\
\hline
\end{tabular}

Mean values were significantly different from those of the alcohol control group: ${ }^{*} P<0.05$. $\dagger$ Mean values were significantly different from those of the normal control group $(P<0.05)$. 

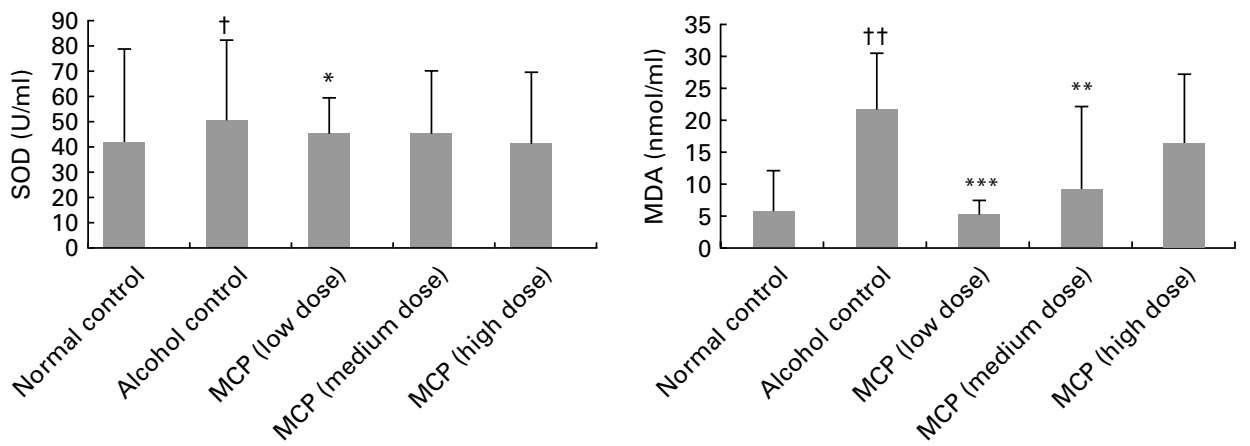

Fig. 1. Effects of marine collagen peptides (MCP) on serum superoxide dismutase (SOD) and malondialdehyde (MDA) levels in rats. Mean values were significantly different from those of the alcohol control group: ${ }^{\star} P<0.05,{ }^{\star \star} P<0.01,{ }^{\star \star \star} P<0.001$. Mean values were significantly different from those of the normal control group $\uparrow P<0.05, \dagger+P<0.01$.

Serum MDA concentration was increased in the alcohol control group $(21.66(\mathrm{SD} 8.93) \mathrm{nmol} / \mathrm{ml})$, compared with the normal control group $(6 \cdot 11(\mathrm{sD} 6 \cdot 38) \mathrm{nmol} / \mathrm{ml})$, but the MDA level was lowered by the MCP intervention significantly $(P<0.01$ in the low- and medium-dose groups, compared with the alcohol control group).

\section{Lipid and protein levels in serum}

Serum TAG and TC levels were significantly increased in the alcohol control group (1.18 (SD 0.29) and 2.64 (SD $0 \cdot 24) \mathrm{mmol} / \mathrm{l})$, compared with the normal control group $(0 \cdot 46$ (sD 0.14) and $1.87($ sD 0.48) mmol/l; Table 4). Meanwhile, MCP reversed the increases in serum TAG and TC levels $(P<0.05$ and $<0.001$, respectively). Serum total proteins and albumin levels were not significantly different in all groups. The results showed that the albumin:globulin ratio of the alcohol control group was higher than that of the normal control group $(P<0.05)$, and this ratio was even higher after the MCP treatment (not significant compared with the alcohol control group).

\section{Activity of alcohol dehydrogenase in liver tissue}

Although there was no significant change in ADH levels between each group, we found a raising trend of $\mathrm{ADH}$ levels in alcohol-treated rats compared with normal control rats $(P=0 \cdot 127$; Fig. 2$)$. Also, the MCP treatment reversed the alcohol-induced change in ADH levels.

\section{Histopathological result}

Histological features of the normal control and alcohol control groups are shown in Fig. 3(a) and (b). There were no pathological changes in the liver of normal control rats. In the rats of the alcohol control group, there were pathological changes in liver tissue characterised by swelling and irregular distribution of the cells. Also, part of the hepatocytes presented fatty degeneration. However, severe pathological changes such as inflammation and apoptosis reported in previous studies were not observed here. The MCP treatment reduced the histopathological changes characterised by more regular hepatic cords and sharp border of the hepatocytes (Fig. 3(c)-(e)).

\section{Discussion}

MCP from fish skin have been used in food processing. The present study was designed to examine the effect of MCP on early alcoholic liver injury. Different methods of building an alcoholic liver injury model have been developed to study the hepatic protectant. In a study by Wang et al. ${ }^{(27)}$, rats were administered orally with alcohol at a dose of $6 \mathrm{~g} / \mathrm{kg}$ body weight for $8 \mathrm{~d}$ to induce liver injury. In another study by Kono et al. ${ }^{(28)}$, high-fat liquid diets were used with ethanol at a dose of $10 \mathrm{~g} / \mathrm{kg}$ continuously for 4 weeks to build a liver injury model. In the present study, female rats were administered with alcohol at a dose of $6 \mathrm{~g} / \mathrm{kg}$ for 4 weeks to cause early liver injury. The results showed a reduced body weight

Table 4. Effects of marine collagen peptides (MCP) on lipid and protein levels in the serum of rats (Mean values and standard deviations, $n 8-11 /$ group)

\begin{tabular}{|c|c|c|c|c|c|c|c|c|c|c|c|}
\hline \multirow[b]{2}{*}{ Groups } & \multirow[b]{2}{*}{$n$} & \multicolumn{2}{|c|}{ TAG $(\mathrm{mmol} / \mathrm{l})$} & \multicolumn{2}{|c|}{$\mathrm{TC}(\mathrm{mmol} / \mathrm{l})$} & \multicolumn{2}{|c|}{$\mathrm{TP}(\mathrm{g} / \mathrm{l})$} & \multicolumn{2}{|c|}{ ALB $(g / l)$} & \multicolumn{2}{|c|}{ A:G ratio } \\
\hline & & Mean & SD & Mean & SD & Mean & SD & Mean & SD & Mean & SD \\
\hline Normal control & 10 & 0.46 & 0.14 & 1.87 & 0.48 & 78.69 & 4.72 & 49.87 & 4.40 & 1.80 & 0.43 \\
\hline $\begin{array}{l}\text { Alcohol control } \\
\mathrm{MCP}\end{array}$ & 11 & 1.18††† & 0.29 & 2.64††† & 0.24 & 78.71 & 3.65 & $53 \cdot 14$ & 3.68 & $2 \cdot 10 \dagger$ & 0.25 \\
\hline Low dose & 8 & $0.71^{\star *}$ & 0.12 & 2.49 & 0.60 & $77 \cdot 25$ & $5 \cdot 15$ & 53.54 & $3 \cdot 16$ & $2 \cdot 27$ & 0.19 \\
\hline Medium dose & 10 & 1.07 & 0.47 & 2.45 & 0.35 & 78.47 & 3.11 & 54.38 & 3.64 & $2 \cdot 27$ & 0.25 \\
\hline High dose & 9 & $0 \cdot 70^{\star \star \star}$ & 0.1 & $2 \cdot 22^{*}$ & 0.31 & $77 \cdot 11$ & 6.48 & 53.74 & 4.83 & 2.33 & 0.33 \\
\hline
\end{tabular}

TC, total cholesterol; TP, total protein; ALB, albumin; A:G, albumin:globulin.

Mean values were significantly different from those of the alcohol control group: ${ }^{\star} P<0.05,{ }^{\star \star} P<0.01,{ }^{\star \star *} P<0.001$.

Mean values were significantly different from those of the normal control group: $\uparrow P<0.05, \dagger \dagger \dagger P<0.001$. 


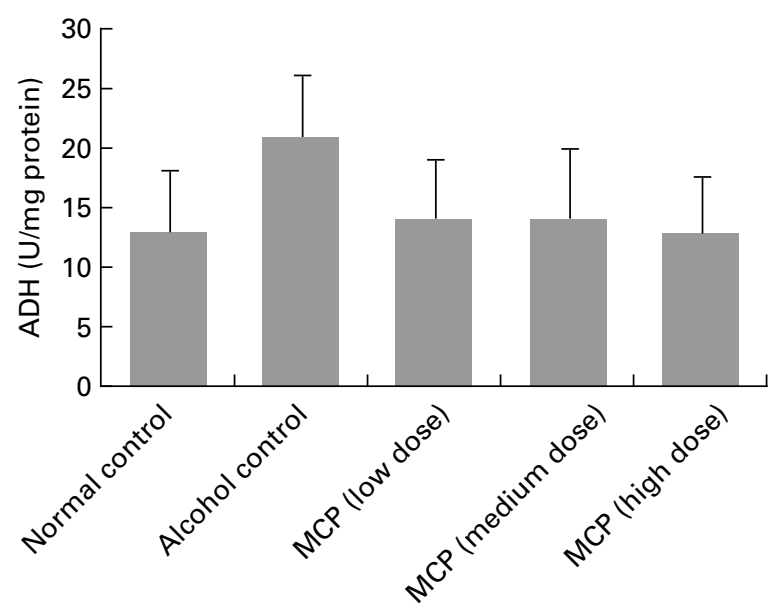

Fig. 2. Effect of marine collagen peptides (MCP) on alcohol dehydrogenase $(\mathrm{ADH})$ levels of liver tissue in rats. Animals were killed $12 \mathrm{~h}$ after the last administration with or without alcohol. Values are means and standard deviations represented by vertical bars $(n 8-11)$. The values were 12.86 (SD 5.27), 17.50 (SD 8.76), 14.08 (SD 5.04), 14.07 (SD 6.06), 13.00 (SD 4.85 ) U/mg protein, respectively.

following the alcohol treatment in the first week, which was not restored by MCP; however, until after 4 weeks, no effect was observed on body weight in either treatment. Besides, the increase in blood biochemical parameters (Table 3) and pathological change in liver injury were observed in the alcohol control group (Fig. 3). The serum marker enzymes (AST and ALT) are cytoplasmic in nature, but upon liver injury, these enzymes enter into the circulatory system due to altered permeability of the membrane ${ }^{(29)}$. Steatosis is usually characterised by a large number of hepatocytes that are occupied by TAG. The MCP exhibited the protective effect on alcoholinduced liver injury by the reversion of these above markers.

Many hypotheses regarding the mechanisms of alcoholinduced hepatocyte injury have been advanced. The most approbatory hypothesis is oxidative stress, which is proposed to be involved in numerous diseases including ALD. Oxidative stress associated with alcohol toxicity is mainly caused by reactive oxygen species, hydroxyethyl radicals and NO in the process of alcohol metabolism. Consequently, breakdown of the cell membrane, hepatic inflammation and hepatocytic apoptosis representing hepatocyte injury by alcohol have been observed $^{(5)}$. The present results showed that alcoholtreated rats possessed a higher MDA level and lower SOD activity in serum than normal control rats, which confirmed the involvement of oxidative stress in alcohol-induced liver injury. MDA is the most abundant by-product of lipid peroxidation, and thus could be considered as an indicator of oxidative stress. Di Luzio \& $\operatorname{Hartman}^{(30)}$ characterised lipid peroxidation after chronic exposure to alcohol for the first time, which was confirmed by other investigators ${ }^{(16,31)}$. SOD is an enzyme that catalytically reduces $\mathrm{O}_{2}^{-}$to $\mathrm{H}_{2} \mathrm{O}_{2}$. Many studies have suggested that alcohol intake lead to the reduction of SOD activity ${ }^{(18,27,32)}$. Based on the above results including the reversed MDA and SOD levels (Fig. 1), it was confirmed that the state of oxidative stress could be restored by the MCP treatment, especially at a low inclusion of $0 \cdot 225 \mathrm{~g} / \mathrm{kg}$ per $\mathrm{d}$. It can be concluded that there is some
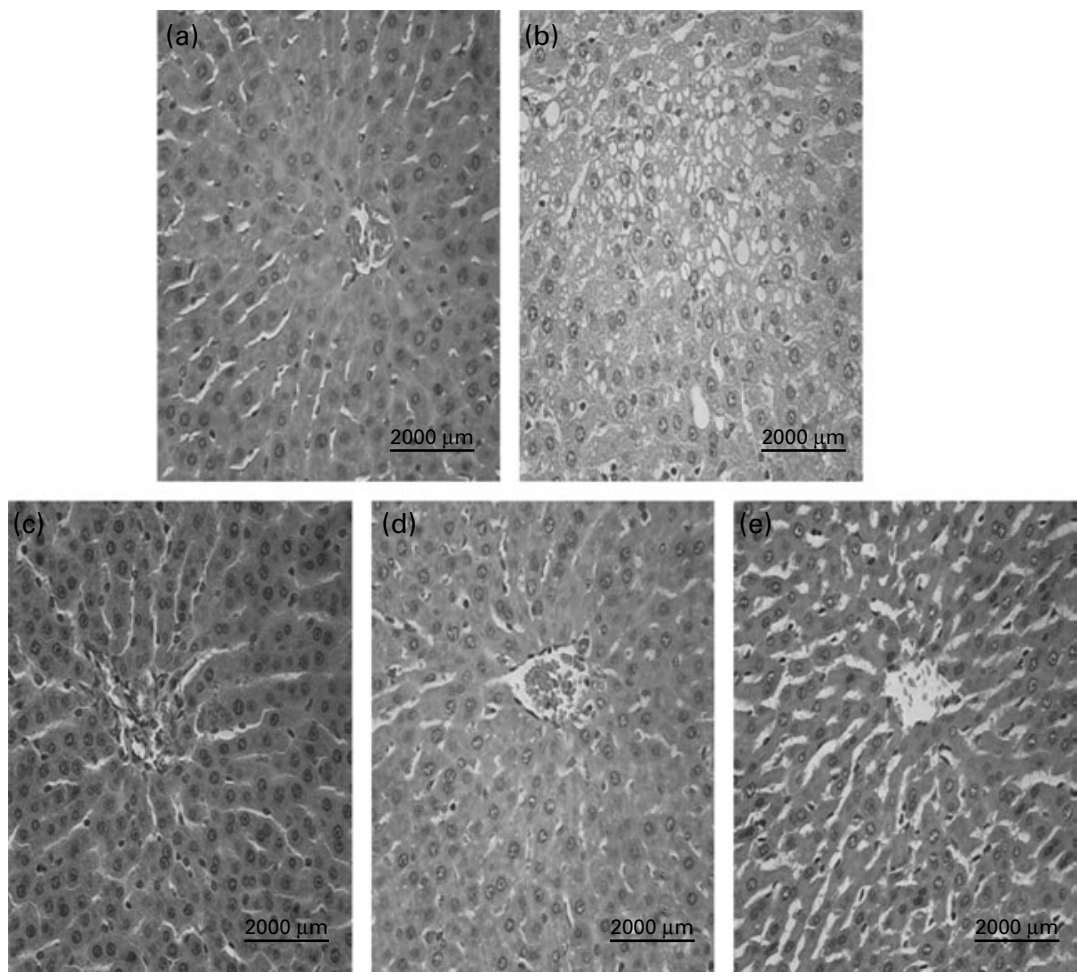

Fig. 3. Representative histopathological changes of the liver in different groups. Histopathological examination of the liver from normal control rats and rats that received alcohol with or without marine collagen peptides (MCP) for 4 weeks $(400 \times)$. (a) Normal control group; (b) alcohol control group; (c) low-dose MCP group; (d) medium-dose MCP group; (e) high-dose MCP group. 
capacity to restore oxidative damage caused by alcohol. A similar antioxidative influence of MCP was observed in previous studies in our laboratory while the capacity was observed in the medium dose of diets supplemented with MCP at concentrations of $4.5 \%{ }^{(20)}$.

Abnormal lipid metabolism can be seen in many patients with $\mathrm{ALD}^{(33)}$. The most common disturbance in lipid metabolism induced by alcohol abuse is excessive accumulation of lipids in the liver (Fig. 3(b)). Alcohol also stimulates lipid peroxidation of the hepatocellular membrane, as discussed previously. Furthermore, serum TAG and TC levels began to change with alcohol administration. Alcohol intake inhibits lipolysis and increases serum TAG levels, with the mechanism still being not clear. It has also been reported that TC and HDL-C had positive correlations with alcohol, but LDL-C showed a less strong negative correlation in human subjects ${ }^{(34-36)}$. Karsenty et al. ${ }^{(37)}$ found that TC increased in baboons pair-fed on cholesterol-free diets containing $50 \%$ of energy either as ethanol or as additional carbohydrate for several years. In the present study, we observed that serum TAG and TC levels rose up after alcohol intake while the MCP treatment reversed the alteration. However, MCP could not make the contents revert to a normal level. A latest study showed that plasma TAG in rats were significantly decreased $2 \mathrm{~h}$ later after the intake of soyabean oil and fish collagen peptide mixtures compared with oil intake only. The group fed an AIN-93G purified diet containing $0 \cdot 17 \%$ fish collagen peptide for $14 \mathrm{~d}$ had lower levels of plasma total lipids and TAG compared with the control group $^{(24)}$. The present study confirmed that lipid metabolism was restored by MCP to alleviate liver injury.

We also found some other hypotheses that might be involved in the effect of MCP on alcohol-treated rats, though not proved this time. The ratio of AST:ALT in the serum of patients with alcoholic hepatitis is generally higher than that of normal subjects and patients with acute liver injury, as described by Nyblom et al. ${ }^{(38)}$ and Das \& Vasudevan ${ }^{(39)}$. In the present study, alcohol induced an increasing AST:ALT ratio compared with normal rats $(P=0 \cdot 271)$. MCP inhibited the increase in ratio, though the difference is not significant (Table 3). In the patients of alcoholic liver injury, inflammation is an important pathological change and is a critical process leading to severe cirrhosis ${ }^{(40)}$. An anti-inflammatory substance has an improvement in early stages of liver injury ${ }^{(41)}$. The results of the AST:ALT ratio suggest that the MCP treatment may be able to alleviate alcohol-induced hepatitis. However, it was not confirmed in the present study. In addition, $\mathrm{ADH}$ in hepatocytes is the specific enzyme that makes alcohol oxidise into acetaldehyde, playing an important role in the process of alcoholic liver injury. Wang et al. ${ }^{(9)}$ found that the activity of hepatic ADH increased gradually along with the occurrence of ALD in rats induced by alcohol at a dose of $8 \mathrm{~g} / \mathrm{kg}$ per $\mathrm{d}$ continuously for 4 weeks. In the present study, there was an increase in the $\mathrm{ADH}$ activity of the alcohol control group compared with that of the normal group (though not significant, $P=0 \cdot 127$ ), whereas the MCP treatment reversed the alcohol-induced increase in ADH activity (Fig. 2). Furthermore, experiments in human subjects and animals have shown that alcohol intake leads to a negative nitrogen balance, in spite of adequate protein intake. In the present study, there was not much difference in the contents of total proteins, albumin and globulin in serum between the alcohol and normal control groups. However, the albumin:globulin ratio was significantly different between the two groups $(P<0 \cdot 05)$. Surprisingly, the albumin:globulin ratio could not be reversed by the MCP treatment and even raised a little (not significant) instead. There is no precise explanation about the alteration. It can be involved in the multi-effects of alcohol, including the immune system, biosynthesis of albumin, absorption of nutriments and so on ${ }^{(8)}$.

It has been well documented that alcohol-induced liver disease results from the dose- and time-dependent consumption of alcohol ${ }^{(42)}$. The results of the AST:ALT ratio and $\mathrm{ADH}$ activity without a significant difference could be attributed to the short time or the low dose of alcohol intake ( $6 \mathrm{~g} / \mathrm{kg}$ per $\mathrm{d}$ for 4 weeks). The design of the present experiment was to build the model of early alcohol-induced liver injury and promote a preliminary study of MCP on rats of this model; consequently, numerous changes in severe alcoholic liver injury reported by other investigators were not observed here.

Being safe and multi-functional, MCP have a strong potential for long-term use as a supplement agent for kinds of illness involving oxidative stress, ALD, for example. However, further studies such as those with a longer-term design and human trials are needed.

In conclusion, the present study indicated that MCP could inhibit early alcoholic liver injury in female rats based on the improvement of oxidative stress and lipid metabolism. Further studies are required to prove whether inflammation and $\mathrm{ADH}$ are involved in the protective mechanisms.

\section{Acknowledgements}

This study was supported (grant 2006BAD27B08) by the Foundation from the Ministry of Science and Technology of the People's Republic of China. The authors gratefully thank the company CF Haishi Biotechnology Limited for providing the samples used in the present study. The authors have no conflicts of interest to disclose. Y. L. gave the original idea and was in charge of the whole trial. B. L. conducted the animal experiment and wrote the manuscript. F. Z., Y. Y., Q. J., Z. Z. and J. W. assisted with the animal trial and biochemical assays. B. L. and F. Z. were responsible for the critical revision of the manuscript.

\section{References}

1. Fan JG, Zhu J, Li XJ, et al. (2005) Prevalence of and risk factors for fatty liver in a general population of Shanghai, China. $J$ Hepatol 43, 508-514.

2. Shaheen NJ, Hansen RA, Morgan DR, et al. (2006) The burden of gastrointestinal and liver diseases, 2006. Am J Gastroenterol 101, 2128-2138.

3. Walsh K \& Alexander G (2000) Alcoholic liver disease. Postgrad Med J 76, 280-286. 
4. Tilg H \& Diehl AM (2000) Cytokines in alcoholic and nonalcoholic steatohepatitis. $N$ Engl J Med 343, 1467-1476.

5. Albano E (2008) Oxidative mechanisms in the pathogenesis of alcoholic liver disease. Mol Aspects Med 29, 9-16.

6. Arteel GE (2003) Oxidants and antioxidants in alcoholinduced liver disease. Gastroenterology 124, 778-790.

7. Yuan G, Gong Z, Li J, et al. (2007) Ginkgo biloba extract protects against alcohol-induced liver injury in rats. Phytother Res 21, 234-238.

8. Bunout D (1999) Nutritional and metabolic effects of alcoholism: their relationship with alcoholic liver disease. Nutrition 15, 583-589.

9. Wang GX, Wang BY \& Liu CR (2002) The relationship between activities of hepatic and gastric alcohol dehydrogenase and occurrence of chronic alcoholic liver disease. Hepatobiliary Pancreat Dis Int 1, 406-410.

10. Bhandarkar MR \& Khan A (2004) Antihepatotoxic effect of Nymphaea stellata willd., against carbon tetrachlorideinduced hepatic damage in albino rats. $J$ Ethnopharmacol 91, 61-64.

11. Golestan Jahromi M, Nabavizadeh F, Vahedian J, et al. (2010) Protective effect of ghrelin on acetaminophen-induced liver injury in rat. Peptides 31, 2114-2117.

12. Sancho-Bru P, Bataller R, Fernandez-Varo G, et al. (2007) Bradykinin attenuates hepatocellular damage and fibrosis in rats with chronic liver injury. Gastroenterology 133, 2019-2028.

13. Allam G (2007) Vasoactive intestinal peptide inhibits liver pathology in acute murine schistosomiasis mansoni and modulates IL-10, IL-12 and TNF-alpha production. Immunobiology 212, 603-612.

14. Luo Q, Wang Y, Feng D, et al. (2009) Vasoactive intestinal peptide attenuates concanavalin A-mediated liver injury. Eur J Pharmacol 607, 226-233.

15. Sonoyama T, Tamura N, Miyashita K, et al. (2009) Inhibition of hepatic damage and liver fibrosis by brain natriuretic peptide. FEBS Lett 583, 2067-2070.

16. Shi Y, Sun J, He H, et al. (2008) Hepatoprotective effects of Ganoderma lucidum peptides against D-galactosamineinduced liver injury in mice. JEthnopharmacol 117, 415-419.

17. Lu ZB, Li Q, Ye BP, et al. (2004) Protective effects of shark hepatic stimulator substance against acute hepatic injury induced by acetaminophen in mice. Yао Хие Хие Вао 39, $17-21$.

18. Guo H, Sun J, He H, et al. (2009) Antihepatotoxic effect of corn peptides against Bacillus Calmette-Guerin/lipopolysaccharide-induced liver injury in mice. Food Chem Toxicol 47, 2431-2435.

19. Zhang F, Wang Z \& Xu S (2009) Macroporous resin purification of grass carp fish (Ctenopharyngodon idella) scale peptides with in vitro angiotensin-I converting enzyme (ACE) inhibitory ability. Food Chem 117, 387-392.

20. Liang J, Pei XR, Wang N, et al. (2010) Marine collagen peptides prepared from chum salmon (Oncorbynchus keta) skin extend the life span and inhibit spontaneous tumor incidence in Sprague-Dawley Rats. J Med Food 13 , $757-770$

21. Tanaka M, Koyama Y \& Nomura Y (2009) Effects of collagen peptide ingestion on UV-B-induced skin damage. Biosci Biotechnol Biochem 73, 930-932.

22. Zolotarev Iu A, Badmaeva KE, Bakaeva ZV, et al. (2006) Short peptide fragments with antiulcer activity from a collagen hydrolysate. Bioorg Khim 32, 192-197.
23. Pei X, Yang R, Zhang Z, et al. (2010) Marine collagen peptide isolated from chum salmon (Oncorbynchus keta) skin facilitates learning and memory in aged $\mathrm{C} 57 \mathrm{BL} / 6 \mathrm{~J}$ mice. Food Chem 118, 333-340.

24. Saito M, Kiyose C, Higuchi T, et al. (2009) Effect of collagen hydrolysates from salmon and trout skins on the lipid profile in rats. J Agric Food Chem 57, 10477-10482.

25. Saunders JB, Davis M \& Williams R (1981) Do women develop alcoholic liver disease more readily than men? Br Med J (Clin Res Ed) 282, 1140-1143.

26. Jarvelainen HA, Lukkari TA, Heinaro S, et al. (2001) The antiestrogen toremifene protects against alcoholic liver injury in female rats. J Hepatol 35, 46-52.

27. Wang H, Feng F, Zhuang BY, et al. (2009) Evaluation of hepatoprotective effect of Zhi-Zi-Da-Huang decoction and its two fractions against acute alcohol-induced liver injury in rats. $J$ Ethnopharmacol 126, 273-279.

28. Kono H, Arteel GE, Rusyn I, et al. (2001) Ebselen prevents early alcohol-induced liver injury in rats. Free Radic Biol Med 30, 403-411.

29. Li YM, Chen SH, Yu CH, et al. (2004) Effect of acute alcoholism on hepatic enzymes and oxidation/antioxidation in rats. Hepatobiliary Pancreat Dis Int 3, 241-244.

30. Di Luzio NR \& Hartman AD (1967) Role of lipid peroxidation in the pathogenesis of the ethanol-induced fatty liver. Fed Proc 26, 1436-1442.

31. Eaton S, Record CO \& Bartlett K (1997) Multiple biochemical effects in the pathogenesis of alcoholic fatty liver. Eur J Clin Invest 27, 719-722.

32. McKim SE, Konno A, Gabele E, et al. (2002) Cocoa extract protects against early alcohol-induced liver injury in the rat. Arch Biochem Biophys 406, 40-46.

33. Lieber C (1974) Effects of ethanol upon lipid metabolism. Lipids 9, 103-116.

34. Castelli WP, Doyle JT, Gordon T, et al. (1977) Alcohol and blood lipids. The cooperative lipoprotein phenotyping study. Lancet 2, 153-155.

35. Veenstra J, Ockhuizen T, van de Pol H, et al. (1990) Effects of a moderate dose of alcohol on blood lipids and lipoproteins postprandially and in the fasting state. Alcohol Alcohol 25, 371-377.

36. Wannamethee G \& Shaper AG (1992) Blood lipids: the relationship with alcohol intake, smoking, and body weight. J Epidemiol Community Health 46, 197-202.

37. Karsenty C, Baraona E, Savolainen MJ, et al. (1985) Effects of chronic ethanol intake on mobilization and excretion of cholesterol in baboons. J Clin Invest 75, 976-986.

38. Nyblom H, Berggren U, Balldin J, et al. (2004) High AST/ALT ratio may indicate advanced alcoholic liver disease rather than heavy drinking. Alcohol Alcohol 39, 336-339.

39. Das SK \& Vasudevan DM (2005) Biochemical diagnosis of alcoholism. Indian J Clin Biochem 20, 35-42.

40. Albano E \& Vidali M (2009) Immune mechanisms in alcoholic liver disease. Genes Nutr 5, 141-147.

41. Mandal P, Pritchard MT \& Nagy LE (2010) Anti-inflammatory pathways and alcoholic liver disease: role of an adiponectin/ interleukin-10/heme oxygenase-1 pathway. World J Gastroenterol 16, 1330-1336.

42. Isayama F, Froh M, Bradford BU, et al. (2003) The CYP inhibitor 1-aminobenzotriazole does not prevent oxidative stress associated with alcohol-induced liver injury in rats and mice. Free Radic Biol Med 35, 1568-1581. 